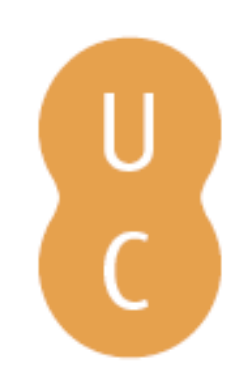

\title{
nommalina
}

\section{A mudança do uso do solo após Alqueva e novos desafios ambientais: o caso do} Olival

Autor(es): $\quad$ Roxo, Maria José; Ventura, José Eduardo

Publicado por: Imprensa da Universidade de Coimbra

URL

persistente: URI:http://hdl.handle.net/10316.2/31203

DOI: $\quad$ DOI:http://dx.doi.org/10.14195/978-989-26-0244-8_96

Accessed : $\quad$ 26-Apr-2023 09:56:44

A navegação consulta e descarregamento dos títulos inseridos nas Bibliotecas Digitais UC Digitalis, UC Pombalina e UC Impactum, pressupõem a aceitação plena e sem reservas dos Termos e Condições de Uso destas Bibliotecas Digitais, disponíveis em https://digitalis.uc.pt/pt-pt/termos.

Conforme exposto nos referidos Termos e Condições de Uso, o descarregamento de títulos de acesso restrito requer uma licença válida de autorização devendo o utilizador aceder ao(s) documento(s) a partir de um endereço de IP da instituição detentora da supramencionada licença.

Ao utilizador é apenas permitido o descarregamento para uso pessoal, pelo que o emprego do(s) título(s) descarregado(s) para outro fim, designadamente comercial, carece de autorização do respetivo autor ou editor da obra.

Na medida em que todas as obras da UC Digitalis se encontram protegidas pelo Código do Direito de Autor e Direitos Conexos e demais legislação aplicável, toda a cópia, parcial ou total, deste documento, nos casos em que é legalmente admitida, deverá conter ou fazer-se acompanhar por este aviso. 


\section{TRUNFOS DE UMA}

\section{EOGRAFIA ACIVA}

\section{DESENVOLVIMENTO LOCAL,}

AMBIENTE,

ORDENAMENTO

E TECNOLOGIA

Norberto Santos

Lúcio Cunha

COORDENAÇÃO 
Maria José Roxo, José Eduardo Ventura

e-GEO - Centro de Estudos de Geografia e Planeamento Regional, Faculdade de Ciências

Sociais e Humanas, Universidade Nova de Lisboa

\section{A MUDANÇA DO USO DO SOLO PÓS ALQUEVA E OS NOVOS DESAFIOS AMBIENTAIS: \\ O CASO DO OLIVAL}

\section{ContextualizaÇão da SituaÇÃo Actual}

As políticas agrícolas da União Europeia tiveram fortes impactos na paisagem rural, com especial destaque para o Alentejo. Nesta região a ocupaçáo dos solos tem reflectido o tipo de apoio ao sector agrícola por parte da Europa e, nos últimos anos, a construção do empreendimento de Alqueva, com a sua vasta albufeira e sistema de rega, tem potenciado a reconversão do uso dos solos, de culturas de sequeiro para culturas de regadio, ou mesmo a passagem a regime de regadio de culturas tradicionais de sequeiro, como é o caso do olival.

O Alentejo é a Região Agrária de Portugal Continental que possui a maior extensão de olival a qual corresponde a $40,8 \%$ do total do País (Figura 1).

Figura 1 - Distribuição da percentagem de olival pelas diferentes Regióes Agrárias de Portugal Continental (www.gppaa.min-agricultura.pt/drural/doc/FileiraAzeiteSantarem.pps)

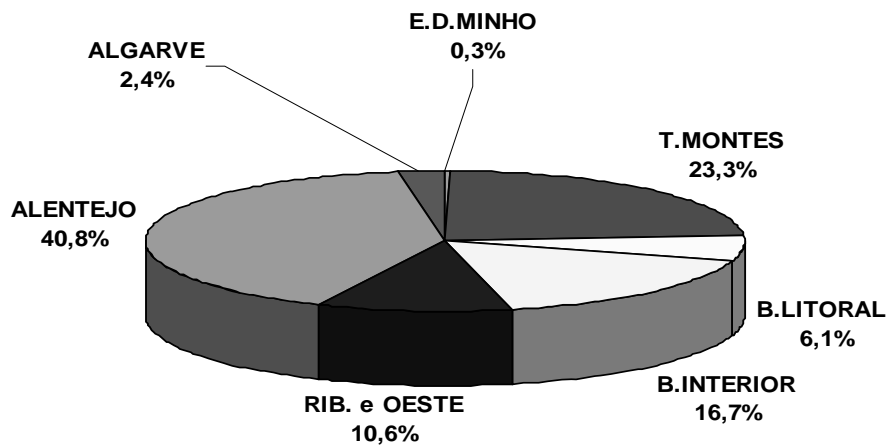

Fonte: INE - IEEA 2005

Também a dimensão média das exploraçóes apresenta os mais elevados valores nesta região, com uma média de 6,9 hectares, num contexto nacional de 2,4 hectares por exploração agrícola. 
Segundo o Anuário de Campanha 2005/2006 (Principais Ajudas Directas), o Alentejo foi a Região Agrária com maior área declarada (53\%) para efeitos de pedidos de ajuda relativos ao olival, com destaque para o escaláo das exploraçóes de maior dimensão (entre 100 e mais de 500 hectares) que, em conjunto, representaram mais de $80 \%$ dessa área.

A implantação do olival aproveita as características edafoclimáticas da região e, apresenta, pela dimensão das exploraçóes a que se associa a disponibilidade de água proporcionada pelo empreendimento do Alqueva, condições para uma forte reestruturação. Esta é igualmente potenciada pelo avanço na modernização do sector em Espanha, onde já não é permitida a plantaçáo de novos olivais pois este país esgotou as quotas de expansão, previstas no âmbito da Política Agrícola Comum da União Europeia.

Deste modo, os agricultores espanhóis começaram a investir na compra de terrenos no Alentejo, conjugando a disponibilidade de terra no mercado a preços bastante inferiores aos praticados no seu país, com a vantagem de em Portugal ainda haver a possibilidade de expansão desta cultura subsidiada.

Os empresários e agricultores portugueses despertaram, entretanto, para as potencialidades proporcionadas pelo sector e, em conjunto com os empresários espanhóis, estão a levar a cabo uma "revolução agrícola" no Alentejo, através do adensamento dos antigos e com a plantaçáo de novos olivais que ocupam cerca de duas dezenas de milhar de hectares em regime intensivo ou super intensivo, com recurso ao regadio.

Esta alteração na olivicultura é já referida no contexto jornalístico como a «nova olivicultura", que resulta da combinaçáo do conhecimento das potencialidades do olival com as novas técnicas agronómicas, adoptando sistemas de produção desenvolvidos para a cultura da vinha.

No sistema intensivo e super intensivo a produtividade aumenta significativamente pois, embora a produção por oliveira seja semelhante nos diversos sistemas, o número de unidades é de 200 a 300 oliveiras por hectare no primeiro destes e, pode ir até 2000 oliveiras por hectare no segundo, diminuindo também, para metade, o número de anos necessários para se atingir o pico de produção. Nos novos olivais, a mecanização, no que se refere à colheita, permite reduzir substancialmente os custos de produçáo tendo em conta que esta tarefa é uma das mais onerosas nos olivais tradicionais.

Assinale-se, ainda, que Portugal apresenta um crónico défice de produção de azeite, que satisfaz pouco mais de metade do consumo, compensado, em grande parte, por importaçóes vindas de Espanha. A actual situação permite que boa parte da nova produção de azeite seja comercializada no País, sendo de assinalar que, dentro de poucos anos a produção pode vir a satisfazer a procura.

\section{EvoluÇão RECEnTE do Olival no Baixo Alentejo}

No conjunto da Região Alentejo, é o Baixo Alentejo que detém a maior área de olival, com $42 \%$ do total (Figura 2) e em que a reestruturação dos antigos olivais e plantaçáo de novos apresenta uma forte dinâmica com impactes assinaláveis na paisagem e nos recursos naturais da regiáo.

No Baixo Alentejo a área de olival é bastante díspar entre os vários concelhos, com as maiores superfícies nos de Serpa, Moura e Beja e uma intenção de novas plantaçóes que, em 2007, era elevada naqueles concelhos, mas com máximo no de Ferreira do Alentejo. 
Apesar deste concelho não estar integrado na área com maior tradição na olivicultura, esta situação justifica-se pela existência de bons solos agrícolas e pelas infra-estruturas de regadio que integram o sistema de rega de Alqueva, o que torna este município num dos mais «apetecíveis» para a implantação de novos olivais (Figura 3).

Figura 2 - Extensão da área de olival do Baixo Alentejo no contexto da NUT III (2007): (www.draal.min-agricultura.pt/produçao/.../olival_total_2007.pdf)

\section{ÁREA DE OLIVAL POR NUT III}

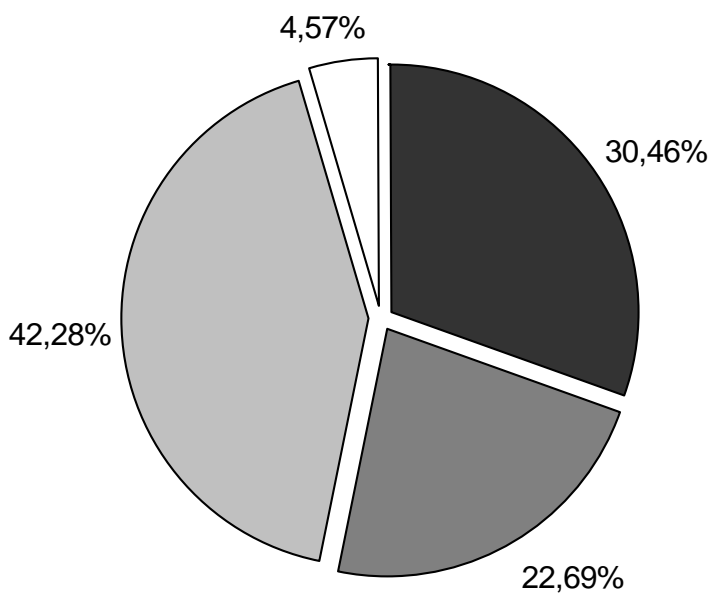

ALTO-ALENTEJO $\square$ ALENTEJO-CENTRAL $\square$ BAIXO-ALENTEJO $\square$ ALENTEJO-LITORAL

Figura 3 - Informação referente ao olival do Baixo Alentejo no contexto da NUT III (2007): (www.draal.min-agricultura.pt/produçao/.../olival_total_2007.pdf)

ÁREA DE OLIVAL - BAIXO ALENTEJO

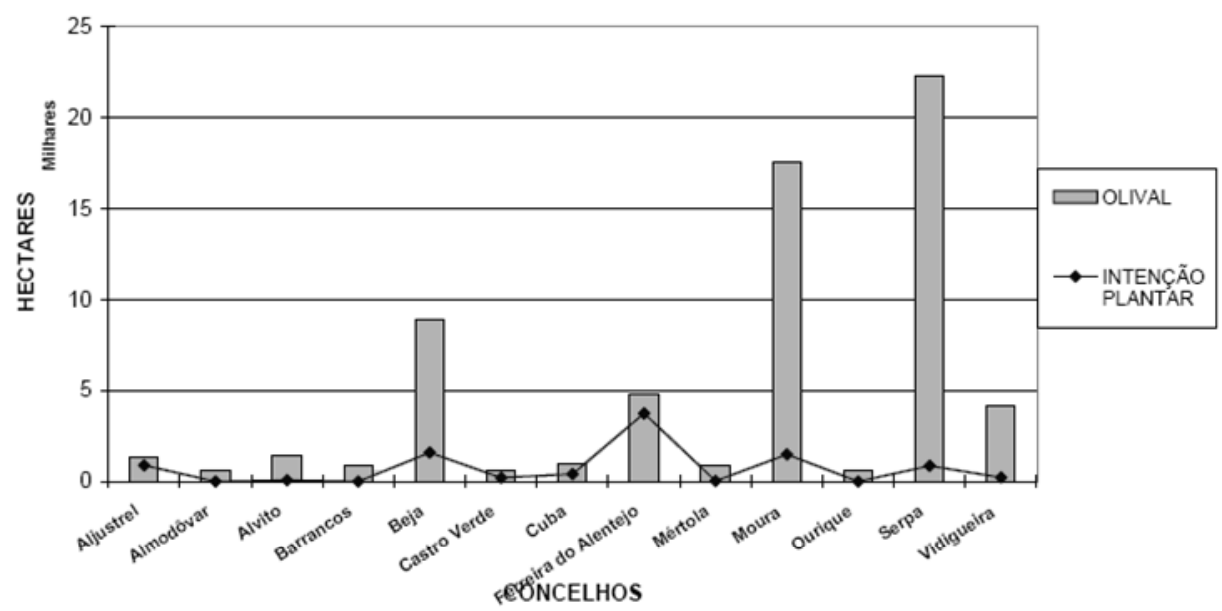




\section{A EXPANSÃo do OliVal Vista Pela COMUnicaÇÃo SOCIAL}

De acordo com estas conjunturas, a evolução da problemática do olival foi equacionada, numa primeira fase, a partir das notícias disponíveis na internet e numa segunda, através da análise da informação publicada online, em jornais de âmbito nacional e régional, de maneira a conhecer-se a percepção da sociedade, bem como as opinióes de técnicos e decisores, sobre os modos de produção e as consequências inerentes não só em termos ambientais mas também económicos e sociais. ${ }^{1}$

A metodologia adoptada passou pela recolha de notícias na internet com base no motor de busca www.google.pt, utilizando as palavras olival intensivo e olival super intensivo entre aspas, condicionando, desta forma, a procura às frases em que as palavras surgissem juntas. A pesquisa é referente ao período de Janeiro de 2003 até Junho de 2009.

Obtiveram-se os seguintes resultados: olival intensivo 1240 ocorrências e olival super intensivo apenas 99. A diferença de resultados é bastante evidente, e explica-se, em parte, pelo facto do olival super intensivo ser um sistema de exploraçáo mais recente.

Como se mencionou anteriormente, foi elaborada igualmente uma pesquisa de notícias publicadas nas ediçóes online dos principais jornais nacionais e regionais (Região Alentejo). Foram encontradas notícias sobre a temática em análise nos seguintes periódicos: (i) Correio da Manhã; (ii) Público; (iii) Expresso; (iv) Jornal de Notícias; (vi) Jornal das Freguesias Alentejo; (v) Diário do Alentejo; (vi) Correio do Alentejo.

Para tratamento da informação obtida foi construída uma base de dados no programa Acess, com os seguintes campos: Título, Data, Informação Geográfica, Dimensão, Nome das herdades, Nacionalidade, Tipo de olival (Figura 4), Espécie de oliveira, Técnica de regadio, Técnica de tratamento, Dados quantitativos, Investimentos, Argumentos a favor, Argumentos contra, Referência a associaçóes, Legislação e Notas.

Figura 4 - Tipos de referências ao olival

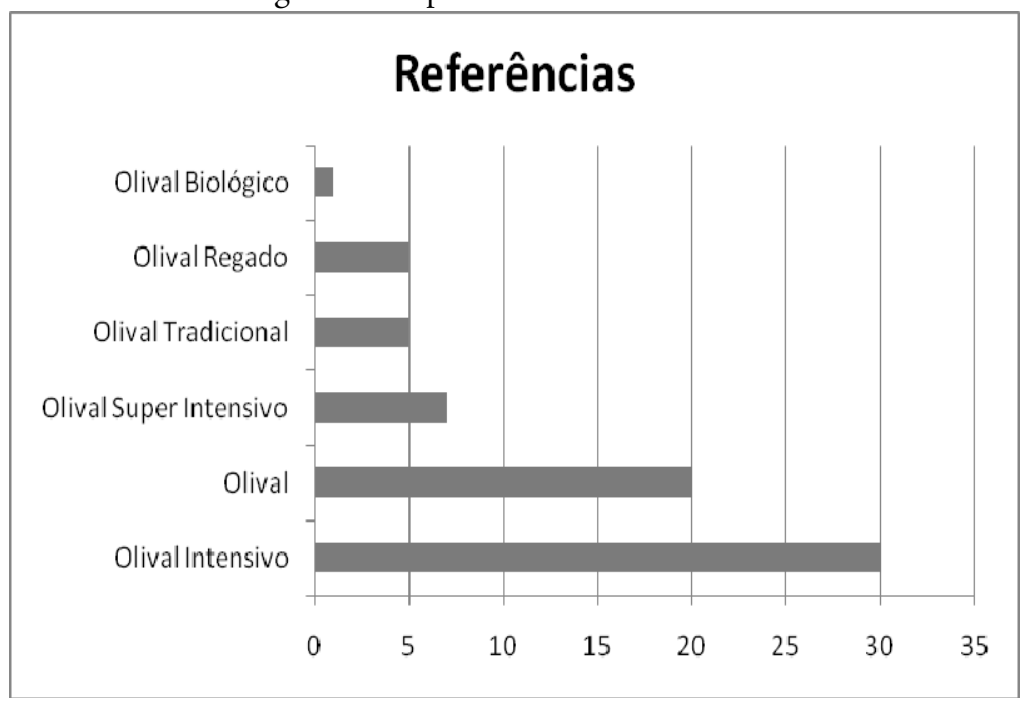

\footnotetext{
${ }^{1}$ Trabalho de pesquisa foi desenvolvido pelo Bolseiro de Iniciação à Investigação, Gonçalo Silva.
} 
Esta sistematização teve por objectivo ajudar na interpretação de cada uma das notícias encontradas. Importa mencionar que foram excluídas as repetições, uma vez que é frequente, no mesmo dia, a mesma notícia ser divulgada por diferentes órgãos de comunicação social.

A leitura atenta das notícias recolhidas foi determinante para conhecer e compreender a forma como os diferentes intervenientes no território (agricultores, autarcas, técnicos, associaçóes não governamentais, entre outros), encaram esta forma de uso do solo, uma vez que a plantação do olival intensivo e super intensivo, veio mudar a paisagem do Alentejo e substituir culturas tradicionais de sequeiro, como os cereais.

Um dos aspectos mais importante corresponde à identificação dos argumentos contra e a favor desta "revolução agrícola», que se identifica pela extensão actual do olival, nesta região do País. Não seria incorrecto afirmar, que se assiste hoje em dia à génese de uma monocultura do olival (Figura 5).

Figura 5 - Olival super intensivo (Foto MJR 2008)

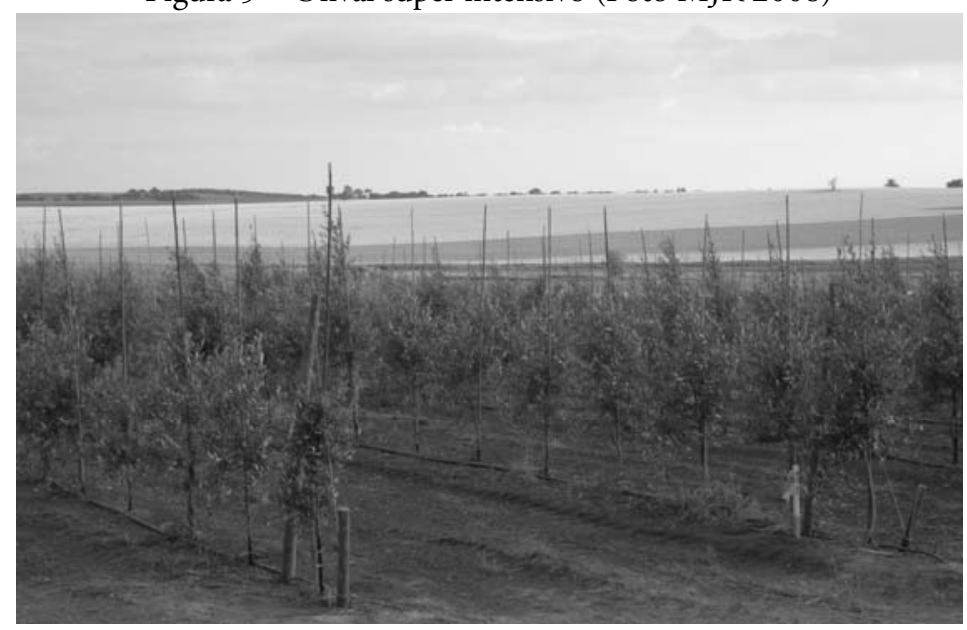

De certa forma os argumentos contra a plantação do olival em sistema intensivo, têm por base argumentos relacionados com questóes ambientais, tais como a contaminação e exploração dos aquíferos, a degradação dos solos e a perda de biodiversidade, enquanto, que os fundamentos a favor assentam em princípios económicos, de rentabilidade das propriedades e de melhores resultados da produçáo e na empregabilidade entre outros aspectos.

O conflito de opinióes revela, sobretudo, a falta de um equilíbrio entre a necessidade de desenvolvimento, neste caso do sector da olivicultura, e a urgência de sustentabilidade ambiental do uso do solo e dos outros recursos incorporados na produçáo do azeite.

Uma das notícias mais relevantes, em 2003, refere-se à tentativa de incentivo por parte do Ministério da Agricultura Desenvolvimento Rural e das Pescas, para a plantação de olival em sistema de exploração intensivo, uma vez que era possível atingir níveis de produção «cinco a seis vezes superior» ao do olival tradicional. O Governo tentou, desta forma, promover a participação dos agricultores portugueses na plantaçáo de novos olivais, num processo iniciado por empresários espanhóis, como se pode deduzir da notícia que se transcreve: 
"Jaime Silva, ministro da Agricultura, elogia o trabalho dos agricultores que apostaram nesta cultura, com destaque para alguns grupos de espanhóis que acabaram por 'abanar' o sector, arrastando consigo investimento nacional, mas chama também a si muitos louros desta vitória: o primeiro mérito é político, da Agenda 2000, que trouxe direitos de plantação de 30 mil novos hectares para Portugal, com ajudas financeiras. Depois ainda houve outro mérito político, que foi considerar o olival uma fileira privilegiada pelo Proder- Programa de Desenvolvimento Rural. E a seguir houve então empresários agrícolas que olharam para o preço do azeite e resolveram avançar para uma pequena revoluçáo no Alentejo, plantando olival» disponível em (http://www.portugalglobal.pt/PT/PortugalNews/Paginas/ /NewDetail.aspx?newId=\%7B67D287A0-737A-4CDE-B570-8ABB68106965\%7D, a 30 de Maio de 2009.

A questão do investimento espanhol, e dos impactes ambientais dos sistemas de exploração intensivo e super intensivo, são os temas mais abordados e sobre os quais se obtem um maior número de notícias (Figura 6).

Figura 6 - Referência a empresários/agricultores espanhóis e portugueses

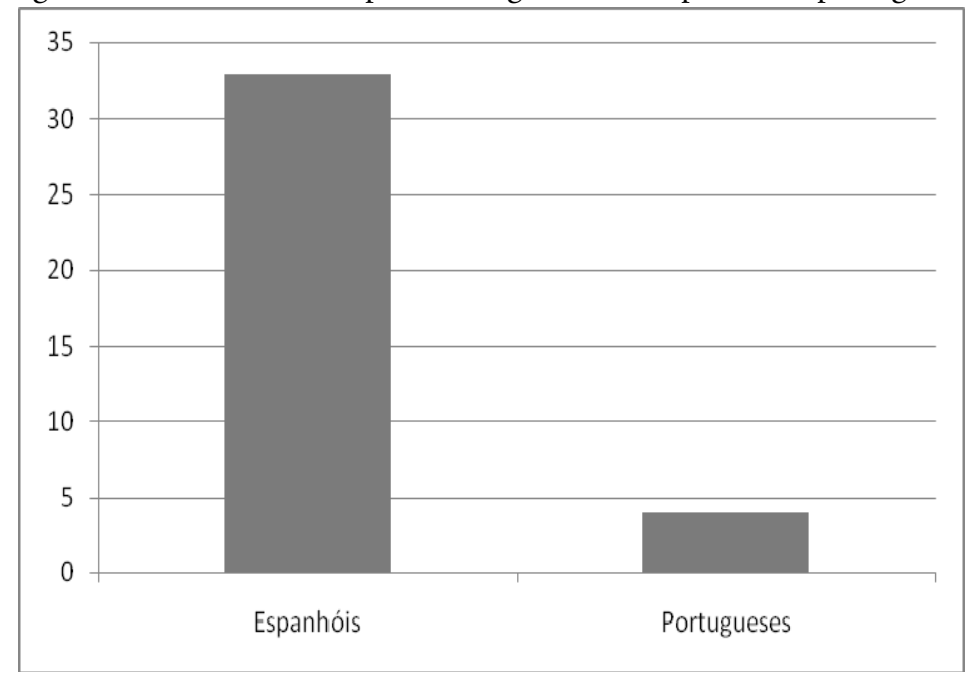

Assim, não surpreende que seja em 2008 que surgem a maioria das notícias referentes ao olival que se está a plantar no Alentejo, tendo em conta o incremento da presença de grandes empresas espanholas em Portugal (aumento da compra de terra) e a visibilidade dos efeitos ambientais desta actividade agro-industrial.

Neste sentido, as notícias são fundamentalmente despoletadas, por Organizaçóes Não Governamentais relacionadas com a defesa do Ambiente, com particular destaque para a Quercus, a Liga de Protecção da Natureza (LPN), Sociedade Portuguesa para o Estudo das Aves (SPEA) e o Centro de Estudos da Avifauna Ibérica (CEAI). Para além das ONGA, existem também referências por parte do Partido Ecologista "Os Verdes» e do Partido Comunista, que colocaram dúvidas, em relação à viabilidade destas exploraçóes onde estão a ser investidos fundos comunitários, e que, em alguns casos, não respeitam a delimitação das áreas da Rede Natura 2000 e da REN (Figura 7). 
Através das notícias é possível identificar os maiores problemas assinalados pelos ambientalistas: (i) o abate de sobreiros e azinheiras sempre, em número superior ao permitido, com a destruição de árvores saudáveis; (ii) a erosão acelerada dos solos, não só durante as fases de preparação do terreno (limpeza do terreno, terraplanagem, sistemas artificiais de drenagem, entre outras acçôes) para a plantação, mas durante todas as fases de tratamento das oliveiras (aplicação de químicos) e de lavouras do solo com a utilização de maquinaria pesada (compactação), durante o ano agrícola; (iii) a utilização dos recursos hídricos superficiais e subterrâneos, em termos da quantidade consumida pela rega (apesar de se ter optado pelo sistema de rega gota-a-gota), assim como as questóes relacionadas com a manutenção das infra-estruturas para o regadio (caso de Alqueva), o preço da água, a construção de redes de drenagem artificiais (consequentemente a destruição de galerias ripícolas), e a contaminação dos recursos hídricos; (iv) perda de biodiversidade, por destruiçáo dos matos e eliminação de habitats; (v) perda de qualidade da paisagem (monotonia nas texturas e cores).

Figura 7 - Número de citaçóes de Organizações não Governamentais e de Partidos Políticos

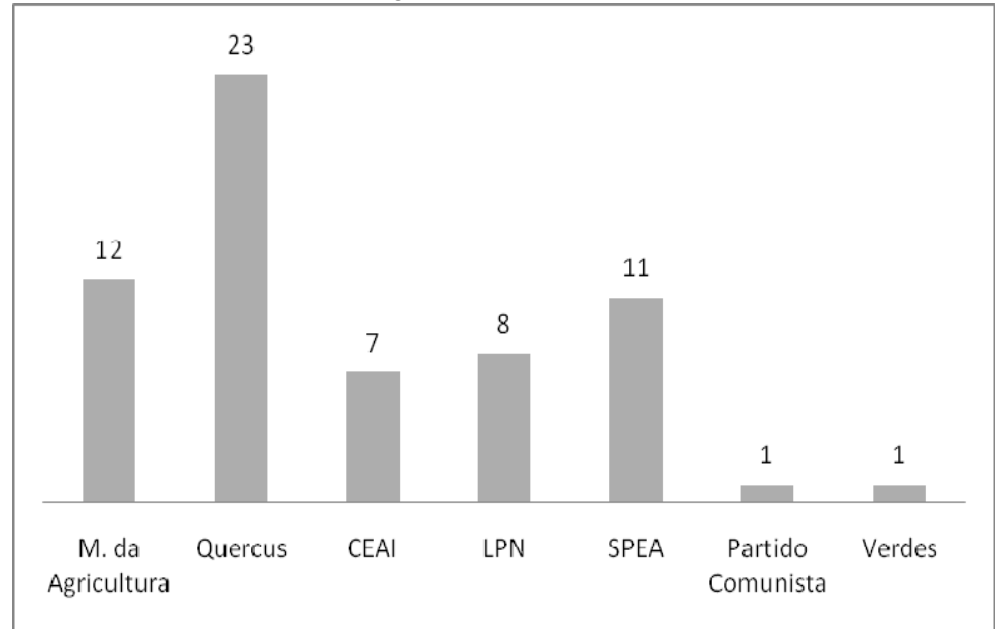

\section{NOTA FINAL}

A água disponibilizada pelo empreendimento do Alqueva, através dos seus perímetros de rega, já construídos e ou em construçáo, associados a solos de qualidade em vastas áreas planas, num país onde o preço da terra por hectare é um dos mais baixos da Europa, foram os grandes factores de expansão da olivicultura em sistemas de exploração intensiva e super intensiva no Alentejo e em particular no Baixo Alentejo.

Contudo, e apesar de todas as notícias divulgadas na imprensa, é fundamental, a avaliação dos impactes e a demonstração das fragilidades e potencialidades deste tipo de produção.

A análise das notícias permitiu identificar as herdades que serão no futuro analisadas como caso de estudo, de maneira a diagnosticar os problemas e as respectivas soluçóes adoptadas para minimizar os seus efeitos sobre o Ambiente. 
Urge avaliar de que forma esta «revolução agrícola» transformou o Baixo Alentejo em termos espaciais, e respectivos reflexos na dinâmica socioeconómica dos concelhos, onde existem grandes herdades produtoras de azeite e azeitona.

\section{REFERÊNCIAS BIBLIOGRÁFICAS}

Anuário de Campanha 2005/06: Principais Ajudas Directas, Coordenação Técnica: Serviços de Estatística, IFADAP/INGA, Maio 2007

Correio do Alentejo, disponível em: http://www.correioalentejo.com.index.php

Correio da Manhã, disponível em: www.correiodamanha.pt

Diário do Alentejo, disponível em: http://www.diarioalentejo.pt/

Expresso, disponível em: http://aeiou.expresso.pt/

Jornal das Freguesias Alentejo, disponível em: http://www.freguesias.com/news.php

Jornal de Notícias, disponível em: www.jn.sapo.pt

Público, disponível em: www.publico.pt 